\title{
Original article \\ Development of a long-life vacuum-packaged ready-to-eat meat product based on a traditional Portuguese seasoned meat
}

\author{
Marta Laranjo, ${ }^{1}$ Ana Gomes, ${ }^{2}$ Maria Eduarda Potes, ${ }^{1,3}$ Maria José Fernandes, ${ }^{4}$ Maria João Fraqueza ${ }^{4}$ \& \\ Miguel Elias ${ }^{1,2} *$ \\ 1 Instituto de Ciências Agrárias e Ambientais Mediterrânicas (ICAAM), Instituto de Investigação e Formação Avançada (IIFA), Universidade \\ de Évora, Pólo da Mitra, Ap. 94, 7006-554 Évora, Portugal \\ 2 Departamento de Fitotecnia, Escola de Ciências e Tecnologia, Universidade de Évora, Pólo da Mitra, Ap. 94, 7006-554 Évora, Portugal \\ 3 Departamento de Medicina Veterinária, Escola de Ciências e Tecnologia, Universidade de Évora, Pólo da Mitra, Ap. 94, 7006-554 Évora, \\ Portugal \\ 4 CIISA, Faculty of Veterinary Medicine, University of Lisbon, Avenida da Universidade Técnica, Pólo Universitário do Alto da Ajuda, \\ 1300-477 Lisbon, Portugal
}

(Received 16 October 2015; Accepted in revised form 17 January 2016)

Summary Carne do alguidar is a Portuguese traditional pork fried meat, usually manufactured for self-consumption purposes. This study developed a ready-to-eat (RTE) meat product, to meet today's consumers' convenience, manufactured at the industrial scale evaluating its quality and shelf life, assessing the effect of vacuum packaging and the use of an antioxidant (50 ppm BHT) to enhance oxidative stability. Physicochemical and microbiological parameters were assessed, and a sensory analysis was performed. Interestingly, no significant differences were recorded between control (non-BHT) and antioxidant (BHT) samples. Microbiological counts remained at low levels throughout the storage period, ensuring the product's required microbiological quality. At later storage stages, higher values of thiobarbituric acidreactive substances arose and off flavours and aromas were perceived. Still, overall appreciation was not affected until 12 months of storage and a significant depreciation was perceived only after 15 months. Fibrousness and rising of off flavours were negatively correlated with overall appreciation.

Keywords Butylated hydroxytoluene, fried pork seasoned meat, lipid oxidation, microbiological quality, sensory evaluation.

\section{Introduction}

Carne do alguidar is a home-made Portuguese fried seasoned meat product preserved in pork lard for several months usually for self-consumption. The preservation of carne do alguidar for long periods results from the effect of both thermal processing of pork meat (fried in lard) and its subsequent conservation in pork lard. High temperatures reached during frying and anaerobic conditions, generated by the immersion of meat in lard, are able to eliminate most microorganisms involved in meat products spoilage. Keeping fried meat in lard also prevents the natural dehydration of the product during storage. This product dates to ancient times, and it originally appeared in response to the need to preserve meat for longer periods. Traditionally, people used to slaughter their homebred pigs at home and, before the use of refrigerators and freezers, carne do alguidar was one possible way to store

*Correspondent: e-mail: elias@uevora.pt pork meat for periods of up to 6 months. This seasoned meat was consumed mainly between the months of December through April to avoid the periods of heat, which accelerate the autoxidation of fat. Currently, this method is no longer used for meat preservation purposes; however, carne do alguidar is a gastronomic speciality still consumed in the Alentejo region.

The potential commercial value of carne do alguidar is the result of two aspects highly valued by today's consumers as it is a ready-to-eat (RTE) traditional product (Stratakos \& Koidis, 2015). However, the manufacturing of carne do alguidar at the industrial level is only possible, if issues regarding its processing are taken into account, to ensure the stability of microbiological and sensory quality throughout the shelf life of the product.

Oxidation is an unavoidable phenomenon in meat industry, which is responsible for food deterioration and shortening the product's shelf life. Even though 
oxidation process is not exclusive to fats, the energy required to trigger lipid oxidation is reduced when compared to other biomolecules such as proteins, carbohydrates and nucleic acids, thus making them more susceptible. This is an important issue for meat products as their composition often includes great amounts of fats, making the lipid fraction oxidation a major concern due to its negative impact. In the course of the lipid oxidation process, numerous undesired compounds such as aldehydes, ketones and alcohols are formed and rancidity arises, as well as several offaroma and off-flavour compounds, which are easily perceived by consumers with a negative impact on the product's sensory properties (Zanardi et al., 2004). On the other hand, some of these compounds possess mutagenic and carcinogenic activities which may pose at risk consumers' health (Weiss et al., 2010). Moreover, associated with fats oxidation, lipids nutritional value is also affected as a result of lower amounts of unsaturated fatty acids (Wood et al., 2003).

Lipid oxidation is affected by substrate availability (lipids and oxygen) as well as by processing conditions. However, antioxidants may be added to meat and meat products to prevent lipid oxidation and retard the development of off flavours (Kumar et al., 2015). Endogenous antioxidants, such as vitamins $\mathrm{A}$ and $\mathrm{E}$, carotenoids, ubiquinol and histidine-containing dipeptides, are some of the antioxidants that naturally occur in meat (Sacchetti et al., 2008; Serpen et al., 2012), known to play an important role in delaying lipid oxidation. Despite this, some additional strategies, such as vacuum packaging, can be undertaken to prevent meat deterioration (Min \& Ahn, 2015). Considering that removing oxygen is often assumed as an inefficient approach (Zanardi et al., 2002; Summo et al., 2006), exogenous antioxidants are used to prevent oxidative rancidity (Timón et al., 2014). The tert-butylhydroquinone (TBHQ), butylated hydroxyanisole (BHA) and butylated hydroxytoluene (BHT) are examples of commercially available antioxidants that are broadly used in meat industry. BHT, in particular, is a phenolic compound whose antioxidant activity relies in donating a hydrogen atom to free radicals which trigger the oxidative process. Its important antioxidant activity has been demonstrated before (Jongjareonrak et al., 2008).

Considering the added commercial value of a RTE traditional meal and the need of technology transfer from the laboratory to the industry, with the consequent upscale, this experimental study was performed at a local meat factory. This study aimed to evaluate the quality and shelf life of carne do alguidar when manufactured at the industrial scale, assessing the effect of a vacuum package and the use of an antioxidant, butylated hydroxytoluene (BHT), to enhance oxidative stability.

\section{Materials and methods}

\section{Carne do alguidar processing and sampling procedures}

For this study, three independent batches of carne do alguidar were processed in a local meat industry, each of them being divided into two equal parts: one containing butylated hydroxytoluene (BHT) [2,6-Bis(1,1dimethylethyl)-4-methylphenol] added to the lard as antioxidant (identified as BHT samples) and the other without antioxidant (named as control samples).

The commercial hybrid Iberian $\times$ Duroc pork meat was manually cut into pieces with approximately $7 \mathrm{~cm}$ and seasoned with pepper (Capsicum annuum L.) paste (containing 5\% sugars) (Incopil, Portugal), white wine, garlic (Allium sativum L.) paste (with $11.6 \%$ sugars) (Incopil, Portugal), salt and laurel powder. Once properly mixed, the meat batter remained under refrigeration $\left(0-5{ }^{\circ} \mathrm{C}\right)$ for 5 days allowing the meat to absorb the flavours. Meat pieces were fried in commercial black pig lard (in a proportion of $80 \%$ regarding to meat weight) for $20 \mathrm{~min}$ at $140{ }^{\circ} \mathrm{C}$. Half of the resulting lard was reserved and added with $50 \mathrm{ppm}$ of BHT. The fried seasoned meat was packed in portions containing $250 \mathrm{~g}$ and fully covered with lard (both control and BHT samples). Once lard was completely solid, polyamide/polyethylene co-extruded film packages (Alempack, Portugal) were sealed under vacuum using the packing machine 700 STE-XL (Turbovac, The Netherlands) and stored at $0-5{ }^{\circ} \mathrm{C}$ for 15 months. Two different samples of meat (removed from the lard) per batch were analysed immediately and at 3, 6, 12 and 15 months of storage.

\section{Physicochemical analyses}

pH was measured with a Crison 507 (Barcelona, Spain) $\mathrm{pH}$ meter according to standard procedures ISO 2917:1999. A hygrometer (Hygroskop Rotronic DT, Zurich, Switzerland), equipped with a WA-40 probe at $25^{\circ} \mathrm{C}$, in its turn was used to determine water activity.

The proximate composition of the RTE carne do alguidar was analysed in accordance with procedures established by the International Organization for Standardization, including moisture content (ISO 1442:1997), total ash (ISO 936:1998), crude protein (ISO 937:1978) and crude lipid content (ISO 1443:1973).

The TBA test was accomplished as described by Fraqueza \& Barreto (2009). Portions of $15 \mathrm{~g}$ of meat samples were homogenised in the presence of trichloroacetic acid, propyl gallate and EDTA, for the extraction of malondialdehyde (MDA). The TBA-reactive substance (TBARS) resulting from reaction of MDA with TBA (red-coloured complex) was determined with 
a UV/Visible Ultrospec 2000 spectrophotometer (Pharmacia Biotech, Buckinghamshire, UK) set for a $538 \mathrm{~nm}$ wavelength and final results expressed in $\mathrm{mg}$ MDA $\mathrm{kg}^{-1}$.

The peroxide values were determined according to the ISO 3960:2007. The fatty fraction was extracted using chloroform and later oxidation of potassium iodate to iodine form by active oxygen in the presence of acetic acid. The amount of iodine generated was then determined by volumetric titration with sodium thiosulphate, and final results expressed in meq $\mathrm{O}_{2} / \mathrm{kg}$.

\section{Microbiological analyses}

For microbiological analyses, $10 \mathrm{~g}$ of sample was homogenised for $90 \mathrm{~s}$ in $90 \mathrm{~mL}$ of sterile peptone water using a Stomacher Masticator (IUL Instruments, Barcelona, Spain). Serial dilutions with peptone water were held, plated and incubated following procedures specific for each microbial group. Total aerobic (mesophiles) and total anaerobic (anaerobes) at $30{ }^{\circ} \mathrm{C}$ counts were performed in tryptone glucose extract agar (TGE) (Scharlau) at $30{ }^{\circ} \mathrm{C}$ for $48 \mathrm{~h}$, wherein the latter were kept under anaerobic conditions, in an AnaeroJar (Oxoid) using an AnaeroGen sachet (Oxoid). TGE (Scharlau) was also used for psychrophiles counts, with incubations carried out at $10{ }^{\circ} \mathrm{C}$ for 7 days. Lactic acid bacteria (LAB) were incubated in Man, Rogosa and Sharpe (MRS) Agar (Scharlau) at $30{ }^{\circ} \mathrm{C}$ for $48 \mathrm{~h}$ under anaerobic conditions (as described above) and yeasts and moulds in Rose Bengal Chloramphenicol (Scharlau) at $25{ }^{\circ} \mathrm{C}$ for $48 \mathrm{~h}$. Listeria monocytogenes enumeration was performed according to standard procedures (ISO 11290:2014).

\section{Sensory evaluation}

Carne do alguidar sensory evaluation was carried out according to ISO $8586: 2012$ in a room especially prepared for the purpose. A group of ten trained panellists (including five men and five women, aged from 40 to 60 years old) were asked to evaluate products in terms of their appearance, off colours, aroma intensity, off aromas, hardness, fibrousness, succulence, flavour intensity, off flavours, salt perception and overall appreciation according to a 0 ('minimum perception') to 100 ('maximum perception') scale. Specifically for hardness and salt perception attributes, panellists were instructed to consider 50 as the optimum value.

Prior to evaluation, carne do alguidar was heated for $30 \mathrm{~s}$ in a microwave oven (Whirlpool 800) preset to $800 \mathrm{~W}$ and immediately served in white dishes (identified with a random three-digit code). Samples were served with mineral water (at room temperature) and unsalted crackers, so panellists could clean their palate between samples.

\section{Statistical analysis}

Data were submitted to analysis of variance (ANOvA) and principal component analysis (PCA), both using Statistica $^{\mathrm{TM}}$ v.8.0 software (StatSoft Inc, Tulsa, OK, 1984-2007). Significant differences $(P<0.05)$ were determined according to Tukey's honest significant differences (HSD) test. Pearson's correlations were also calculated for a significance level of $P=0.05$.

\section{Results and discussion}

The proximate analysis of carne do alguidar (Table 1) showed no significant differences between control and BHT samples $(P>0.05)$. The lipid fraction was the most abundant corresponding in average to 36.42 and $37.28 \%$ (found in control and BHT samples, by the same order). In our samples, the moisture content represented around $35 \%$, while the protein fraction was about $24 \%$.

With the purpose of evaluating quality and shelf life of this new commercial RTE meat product, physicochemical parameters $\left(\mathrm{a}_{\mathrm{W}}, \mathrm{pH}, \mathrm{TBARS}\right.$ and peroxide value) and microbiota were assessed in the final product throughout the storage period. Moreover, sensory evaluation was also carried out, in terms of product's appearance, aroma, flavour and texture.

As shown in Fig. 1, aw and $\mathrm{pH}$ of the fried seasoned meat did not change significantly over the 15 months of storage, irrespective of addition, or not, of the antioxidant BHT. Probably due to the osmotic gradient established between meat and its surrounding environment, water activity decreased over time, yet no significant differences were found between the final product under vacuum at 0 and 15 months of storage $(P>0.05)$. The evolution of $\mathrm{a}_{\mathrm{W}}$ was similar for both control and BHT samples. Regarding $\mathrm{pH}$ values, they were not significantly different and only showed slight variations ranging between 6.05 and 6.12 . The stability

Table 1 One-way anova for Carne do alguidar proximate composition $(\mathrm{g} / 100 \mathrm{~g})$

\begin{tabular}{lrrl}
\hline & \multicolumn{1}{l}{ Control } & \multicolumn{1}{l}{ BHT } & Significance \\
\hline Moisture & $35.37 \pm 4.44$ & $35.32 \pm 4.76$ & $\mathrm{~ns}$ \\
Fat & $36.42 \pm 4.16$ & $37.28 \pm 4.78$ & $\mathrm{~ns}$ \\
Protein & $24.07 \pm 0.44$ & $23.67 \pm 0.42$ & $\mathrm{~ns}$ \\
Ash & $3.09 \pm 0.21$ & $3.17 \pm 0.16$ & $\mathrm{~ns}$ \\
$\mathrm{CH}^{*}$ & $1.07 \pm 0.39$ & $0.69 \pm 0.35$ & $\mathrm{~ns}$ \\
\hline
\end{tabular}

Ns, not significant.

Data are given as mean $\pm \operatorname{SD}(n=6)$.

${ }^{*} \mathrm{CH}-$ Carbohydrates 
Figure 1 Mean (a) $\mathrm{a}_{\mathrm{w}}$ and (b) $\mathrm{pH}$ values during storage. Data are given as means $(n=6)$, where vertical bars denote 0.95 confidence intervals. Different letters denote significantly different arithmetic means (HSD test, $P=0.05$ ) (a)

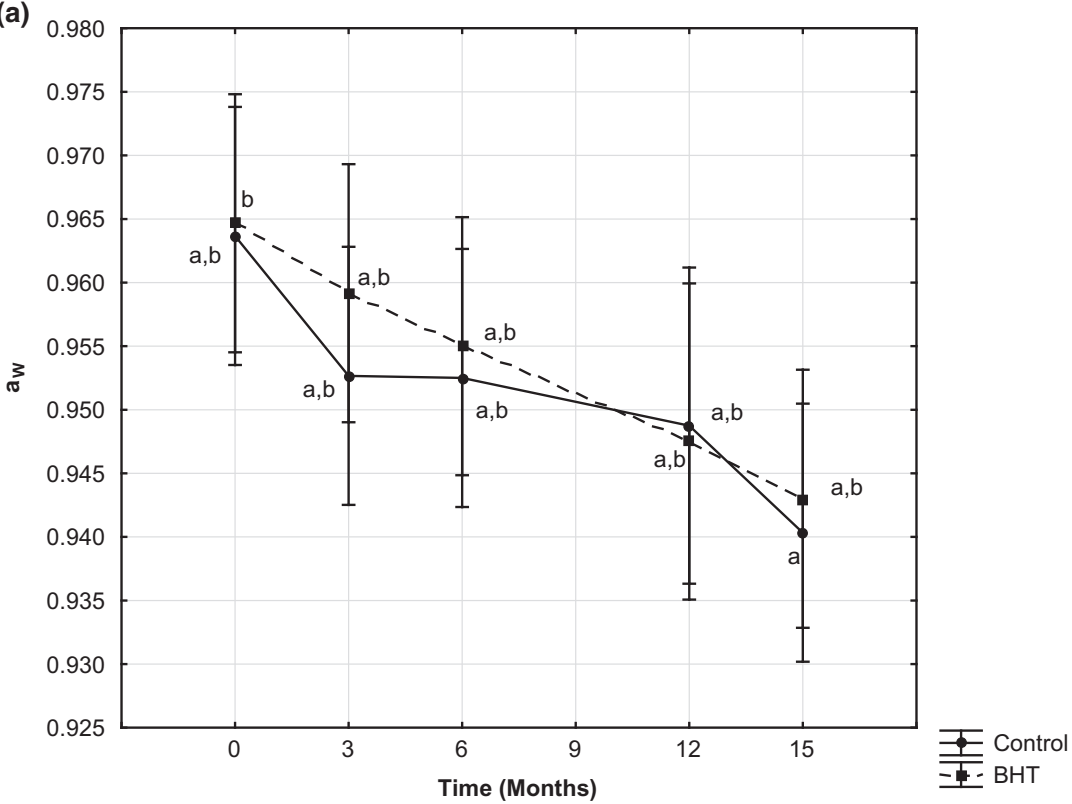

(b)

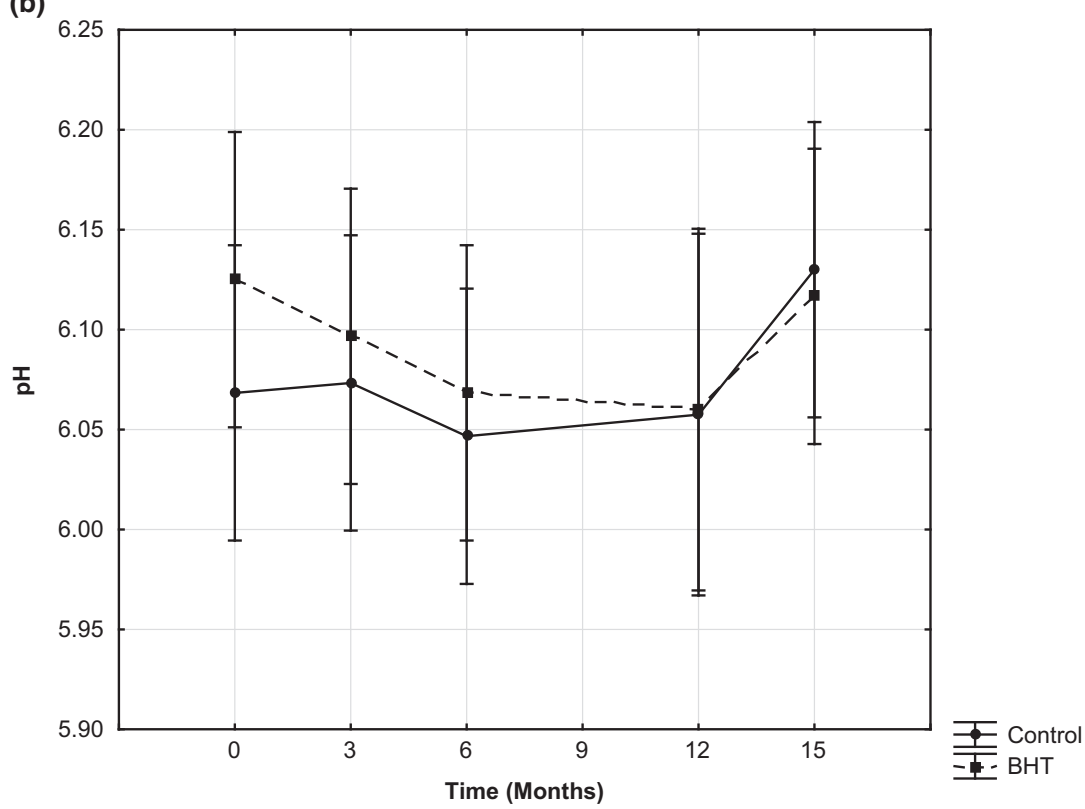

of $\mathrm{pH}$ values is related to the observed lack of microbial development, namely for LAB (Table 2). Based on the ANOVA statistical analysis, no significant differences were found for microbial counts during the time that carne do alguidar was kept under chilled storage, regardless of the considered microbial group (Table 2). During the first months of storage, a slight $(P>0.05)$ decrease was observed for all microbial groups that lasted for 3 months (as observed for psychrophiles, yeasts or even longer mesophiles, LAB and anaerobes). However after this initial period, microbial counts increased again. While for psychrophiles, it occurred just after the first trimester, and for mesophiles and LAB, it was only observed after 12 and 15 months, respectively, with the highest microbial loads being detected at the later sampling time (15 months). Anaerobic bacteria and yeasts counts were the exception as they increased and declined consecutively throughout carne do alguidar storage period as a result of vacuum packaging. In general, the increased microbial counts leaded to higher microbial loads at the end of the storage period when compared to those found 


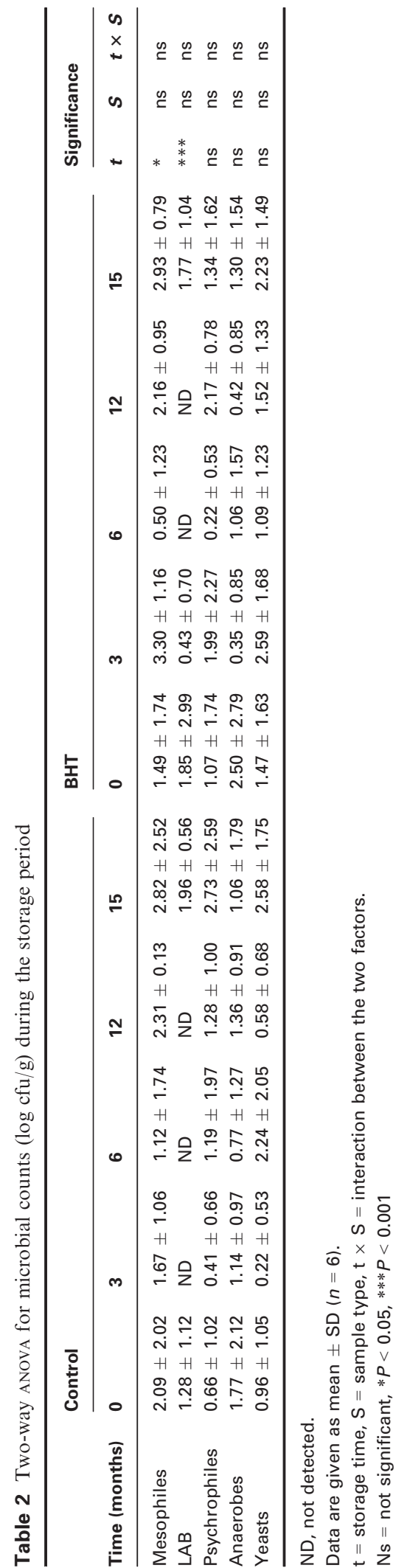

in the beginning of this study $(t=0)$, with the exception of anaerobes. No moulds were detected. Moreover, no changes were observed as a result of BHT addition, as a similar evolution of microbial load was observed for both sample types. Listeria monocytogenes was not detected throughout the product's shelf life. This is in agreement with the microbiological criteria set for RTE food products in the European Regulation (EC) 2073/2005 (2005), which determines that L. monocytogenes counts must not surpass the maximum of $100 \mathrm{cfu} \mathrm{g}^{-1}$.

To our knowledge, there are no published studies regarding the development of long-life vacuumpackaged RTE meat product based on a traditional Portuguese seasoned meat such as carne do alguidar available; in fact, the microbial load found in our samples (Table 2) is similar or even lower than those disclosed for other cooked meat products vacuum packaged and stored under refrigeration (Cachaldora et al., 2013; del Olmo et al., 2014). The application of vacuum package contributed to keep products microbial stability, which Paleari et al. (2004) also found to be effective on pork lard conservation. Therefore, the combination of anaerobic conditions, with low temperatures for preservation of cooked seasoned meat, was shown to be effective in preventing growth of most microbial groups, thus ensuring the necessary microbiological stability.

The lard used in the frying process and later preservation of carne do alguidar may undergo a series of chemical reactions regarding to oxidative degradation of fatty acids, affecting products' quality, especially in products with extended storage periods. Indeed, only storage time had a significant effect on lipids oxidation $(P<0.05)$. Regarding control samples, as shown in Table 3, TBARS results significantly decreased at 6 months of storage $(P<0.05)$, after a slight increase observed over the first trimester (from 0.66 to $0.77 \mathrm{mg}$ MDA kg-1). According to our results, such progression over this period of time revealed to be somewhat different for BHT samples, for which products measured free MDA initial contents $\left(0.71 \mathrm{mg} \mathrm{MDA} \mathrm{kg}{ }^{-1}\right)$ consistently decreased during the first 6 months of storage $(0.23 \mathrm{mg}$ MDA kg-1). However, for both control and BHT samples, TBARS values increased from six to 12 months, not suffering any significant changes from 12 to 15 months of storage. Irrespective of adding BHT to the lard where carne do alguidar was preserved, no differences were detected after the 15th month of storage in TBARS values. As shown in Table 3, free MDA contents for these samples were $1.13 \mathrm{mg} \mathrm{MDA} \mathrm{kg}$ in BHT samples and $1.16 \mathrm{mg}$ MDA kg ${ }^{-1}$ in control samples. Even though the reported increment on TBARS values in later storage stages always remained below the cut-off value of $2.0 \mathrm{mg} \mathrm{MDA} \mathrm{kg}^{-1}$ at which rancidity may be detected 


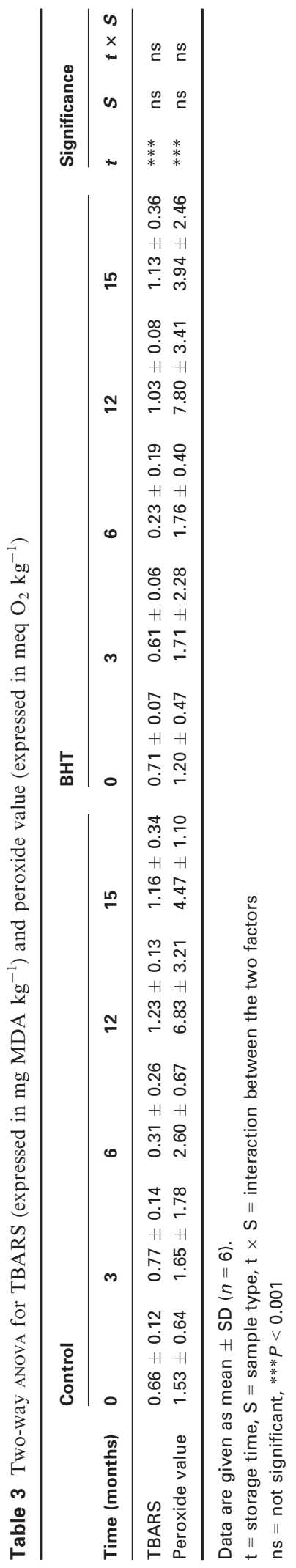

by consumers (Wood et al., 2003). Concerning peroxide values, there was a consistent increase $(P>0.05)$ during the first 12 months of storage (with a particular focus in the last semester), time when the maximum value was reached $\left(6.83\right.$ and 7.80 meq $\mathrm{O}_{2} \mathrm{~kg}^{-1}$, in control and BHT samples, respectively). A slight decrease occurred for samples stored for 15 months, for levels comparable $(P>0.05)$ to those measured for final product $(t=0)$, both for control and BHT samples. This reported oxidation stability is probably related to the antioxidant activity effect of Maillard reaction products (Ramírez et al., 2004; Serpen et al., 2012), as a considerable amount of sugars was added (high \% of sugars in garlic and pepper pastes), but also due to antioxidant activity of the added wine and garlic. Maillard reaction is important for colour, flavour and aroma development of fried meat products. High temperatures initiate the reaction between reducing sugars and amino groups existent in meat. At high temperatures, cell structures are broken, allowing the interaction between lipids and the existing oxidising groups. For this reason, the process of lipid oxidation in cooked meat is faster than in fresh meat (Ramírez et al., 2004). In particular, for cooked meat products, which are chilled and then reheated, unpleasant aromas, known as 'warmed-over-flavours', quickly arise.

During carne do alguidar storage, various sensory characteristics related with products aroma, appearance and texture were evaluated by a group of experienced panellists, whose mean scores are summarised in Table 4. Sensory evaluation data were initially analysed with a two-way ANOVA; still from the statistical evaluation, it was clear that storage time was the only factor showing a significant $(P<0.05)$ effect regarding sensory parameters. Moreover, both sample type and respective 'storage time $\times$ sample type' combination had no influence in the scores attributed by the panellists. Such results were already expected; as, as shown in Table 4, for similar storage times, identical scores were given.

As factors' interaction was not significant $(P>0.05)$, for physicochemical, microbiological and sensory data, all results were submitted to one-way ANOvAs, which are summarised in Table 5.

Still regarding sensory data, both flavour/aroma and texture were affected over time (Table 5). In particular, aroma intensity, fibrousness, succulence, flavour intensity and overall appreciation were the most affected attributes (Table 5). The main changes were noted during the first trimester, where important losses regarding aroma intensity, succulence, flavour and intensity had occurred $(P<0.05)$. On the other hand, during this same period of time, a marked increase in carne do alguidar fibrousness was also perceived. Together, the evolution of these attributes has led to lower overall appreciations rated by the panellists' 
Ready-to-eat traditional seasoned meat M. Laranjo et al.

Table 4 Two-way ANOva for sensory attributes throughout the storage period.

\begin{tabular}{|c|c|c|c|c|c|c|c|c|c|c|c|c|c|}
\hline \multirow[b]{2}{*}{ Time (months) } & \multicolumn{5}{|l|}{ Control } & \multicolumn{5}{|l|}{ BHT } & \multicolumn{3}{|c|}{ Significance } \\
\hline & 0 & 3 & 6 & 12 & 15 & 0 & 3 & 6 & 12 & 15 & $t$ & $s$ & $t \times s$ \\
\hline Appearance & $72 \pm 14$ & $67 \pm 13$ & $72 \pm 15$ & $68 \pm 16$ & $70 \pm 15$ & $73 \pm 12$ & $68 \pm 13$ & $67 \pm 14$ & $70 \pm 15$ & $69 \pm 13$ & ns & ns & ns \\
\hline Off colours & $0 \pm 0$ & $0 \pm 0$ & $1 \pm 3$ & $1 \pm 3$ & $0 \pm 2$ & $0 \pm 0$ & $1 \pm 4$ & $0 \pm 1$ & $0 \pm 0$ & $0 \pm 1$ & ns & ns & ns \\
\hline Aroma intensity & $74 \pm 10$ & $64 \pm 17$ & $69 \pm 10$ & $63 \pm 16$ & $67 \pm 15$ & $73 \pm 14$ & $66 \pm 17$ & $68 \pm 11$ & $63 \pm 16$ & $66 \pm 14$ & $* *$ & ns & $\mathrm{ns}$ \\
\hline Off aromas & $0 \pm 1$ & $1 \pm 5$ & $0 \pm 1$ & $2 \pm 9$ & $1 \pm 2$ & $0 \pm 1$ & $0 \pm 2$ & $0 \pm 1$ & $1 \pm 3$ & $1 \pm 4$ & ns & ns & ns \\
\hline Hardness & $53 \pm 13$ & $44 \pm 25$ & $53 \pm 15$ & $54 \pm 16$ & $57 \pm 12$ & $55 \pm 10$ & $44 \pm 27$ & $56 \pm 11$ & $54 \pm 13$ & $55 \pm 10$ & ns & ns & ns \\
\hline Fibrousness & $24 \pm 24$ & $36 \pm 29$ & $34 \pm 26$ & $35 \pm 26$ & $37 \pm 29$ & $21 \pm 22$ & $38 \pm 31$ & $32 \pm 28$ & $35 \pm 27$ & $37 \pm 29$ & * & ns & ns \\
\hline Succulence & $69 \pm 15$ & $55 \pm 21$ & $58 \pm 21$ & $60 \pm 20$ & $56 \pm 20$ & $66 \pm 18$ & $57 \pm 23$ & $65 \pm 17$ & $61 \pm 19$ & $58 \pm 20$ & $* *$ & ns & ns \\
\hline Flavour intensity & $78 \pm 9$ & $68 \pm 11$ & $70 \pm 13$ & $70 \pm 11$ & $70 \pm 12$ & $76 \pm 10$ & $68 \pm 18$ & $71 \pm 10$ & $68 \pm 13$ & $69 \pm 12$ & ns & ns & ns \\
\hline Off flavours & $1 \pm 2$ & $1 \pm 3$ & $0 \pm 1$ & $2 \pm 5$ & $2 \pm 4$ & $0 \pm 1$ & $1 \pm 3$ & $1 \pm 2$ & $4 \pm 11$ & $5 \pm 14$ & * & ns & ns \\
\hline Salt perception & $56 \pm 8$ & $55 \pm 13$ & $53 \pm 7$ & $56 \pm 9$ & $54 \pm 9$ & $56 \pm 11$ & $52 \pm 14$ & $55 \pm 8$ & $56 \pm 9$ & $54 \pm 9$ & ns & ns & ns \\
\hline Overall appreciation & $75 \pm 15$ & $66 \pm 13$ & $70 \pm 15$ & $65 \pm 16$ & $62 \pm 15$ & $75 \pm 13$ & $66 \pm 16$ & $73 \pm 9$ & $65 \pm 17$ & $59 \pm 20$ & $* * *$ & ns & $\mathrm{ns}$ \\
\hline
\end{tabular}

Data are given as mean $\pm \mathrm{SD}(n=6)$.

$\mathrm{t}=$ storage time, $\mathrm{S}=$ sample type, $\mathrm{t} \times \mathrm{S}=$ interaction between the two factors

ns $=$ not significant, $* P<0.05, * * P<0.01, * * * P<0.001$

Table 5 One-way ANOva for physicochemical, microbiological and sensory data throughout the storage period

\begin{tabular}{|c|c|c|c|c|c|c|}
\hline \multirow[b]{2}{*}{ Parameters } & \multicolumn{5}{|l|}{ Time (months) } & \multirow[b]{2}{*}{ Significance } \\
\hline & 0 & 3 & 6 & 12 & 15 & \\
\hline$a_{w}$ & $96.42^{\mathrm{C}} \pm 1.58$ & $95.59^{b, c} \pm 0.95$ & $95.38^{\mathrm{a}, \mathrm{b}} \pm 0.97$ & $94.81^{\mathrm{a}, \mathrm{b}} \pm 0.84$ & $94.17^{\mathrm{a}} \pm 1.33$ & $* * *$ \\
\hline $\mathrm{pH}$ & $6.10 \pm 0.11$ & $6.09 \pm 0.10$ & $6.06 \pm 0.11$ & $6.06 \pm 0.02$ & $6.12 \pm 0.04$ & ns \\
\hline Mesophiles & $1.79^{\mathrm{a}, \mathrm{b}} \pm 1.82$ & $2.49^{a, b} \pm 1.36$ & $0.81^{\mathrm{a}} \pm 1.47$ & $2.24^{a, b} \pm 0.63$ & $2.87^{b} \pm 1.79$ & $*$ \\
\hline LAB & $1.57^{b} \pm 2.17$ & $0.22^{\mathrm{a}} \pm 0.52$ & ND & ND & $1.86^{b} \pm 0.80$ & $* * *$ \\
\hline Psychrophiles & $0.87 \pm 1.38$ & $1.20 \pm 1.79$ & $0.70 \pm 1.47$ & $1.73 \pm 0.95$ & $2.03 \pm 2.18$ & ns \\
\hline Anaerobes & $2.14 \pm 2.39$ & $0.74 \pm 0.96$ & $0.91 \pm 1.37$ & $0.89 \pm 0.96$ & $1.18 \pm 1.60$ & ns \\
\hline Yeasts & $1.22 \pm 1.33$ & $1.40 \pm 1.72$ & $1.67 \pm 1.72$ & $1.05 \pm 1.10$ & $2.41 \pm 1.56$ & ns \\
\hline TBARS & $0.69^{b} \pm 0.10$ & $0.69^{b} \pm 0.13$ & $0.27^{a} \pm 0.22$ & $1.13^{\mathrm{c}} \pm 0.12$ & $1.14^{\mathrm{c}} \pm 0.33$ & $* * *$ \\
\hline Peroxide value & $1.37^{\mathrm{a}} \pm 0.56$ & $1.68^{\mathrm{a}} \pm 1.95$ & $2.18^{a} \pm 0.68$ & $7.31^{\mathrm{c}} \pm 2.43$ & $4.20^{\mathrm{b}} \pm 1.84$ & $* * *$ \\
\hline Appearance & $72 \pm 13$ & $67 \pm 13$ & $70 \pm 15$ & $69 \pm 16$ & $69 \pm 14$ & ns \\
\hline Off colour & $0 \pm 0$ & $1 \pm 3$ & $0 \pm 2$ & $0 \pm 2$ & $0 \pm 2$ & ns \\
\hline Aroma intensity & $73 b \pm 12$ & $65^{a} \pm 16$ & $68^{a, b} \pm 11$ & $63^{a} \pm 16$ & $67^{a, b} \pm 15$ & $* *$ \\
\hline Off aroma & $0 \pm 1$ & $1 \pm 4$ & $0 \pm 1$ & $1 \pm 3$ & $1 \pm 3$ & ns \\
\hline Hardness & $54 \pm 12$ & $55 \pm 18$ & $55 \pm 13$ & $54 \pm 14$ & $56 \pm 11$ & ns \\
\hline Fibrousness & $22^{\mathrm{a}} \pm 22$ & $37^{b} \pm 29$ & $33^{a, b} \pm 27$ & $35^{a, b} \pm 26$ & $37^{b} \pm 29$ & * \\
\hline Succulence & $69^{b} \pm 16$ & $56^{a} \pm 22$ & $62^{\mathrm{a}, \mathrm{b}} \pm 19$ & $60^{\mathrm{a}, \mathrm{b}} \pm 19$ & $57^{a} \pm 20$ & $* *$ \\
\hline Flavour intensity & $77^{b} \pm 9$ & $69^{a} \pm 14$ & $71^{a} \pm 11$ & $69^{a} \pm 12$ & $70^{a} \pm 12$ & $* *$ \\
\hline Off flavour & $0^{a, b} \pm 2$ & $1^{\mathrm{a}} \pm 3$ & $1^{a} \pm 2$ & $3^{a, b} \pm 9$ & $3^{b} \pm 9$ & * \\
\hline Salt perception & $56 \pm 10$ & $53 \pm 13$ & $54 \pm 8$ & $56 \pm 9$ & $54 \pm 9$ & ns \\
\hline Overall appreciation & $76^{c} \pm 13$ & $66^{a, b} \pm 15$ & $72^{\mathrm{b}, \mathrm{c}} \pm 12$ & $65^{a} \pm 16$ & $61^{a} \pm 17$ & $* * *$ \\
\hline
\end{tabular}

ND, not detected.

Data are given as mean $\pm \operatorname{SD}(n=6)$.

ns $=$ not significant, $* P<0.05, * * P<0.01, * * * P<0.001$

In the same line, different letters represent significantly different means.

group. In fact, for all these attributes the highest rates were found in 'fresh' products $(t=0)$, except for fibrousness.

During the second trimester of products' storage, overall appreciation slightly recovered, due to more positive evaluations, namely higher aroma intensity, succulence and flavour intensity and lower meat fibrousness. After this period, global appreciation rates consecutively declined until 15 months of storage, where the lowest rates were scored. At this point, a few panellists denoted some rancidity and a musty taste, which together contributed to a depreciation in the products' acceptability. Moreover, according to the panellists' additional comments, 'warmed-over-flavours' 
Figure 2 Principal component analysis: projection of the variables and samples on the factor plane, considering the two main factors. Letters $\mathrm{C}$ and $\mathrm{B}$ represent the code for 'control samples' (C) and 'BHT samples' (B), respectively, while numbers correspond to storage time (in months). A: appearance, OC: off colour, AI: aroma intensity, OA: off aroma, H: hardness, F: fibrousness, S: succulence, FI: flavour intensity, OF: off flavour, SP: salt perception, OAp: overall appreciation.

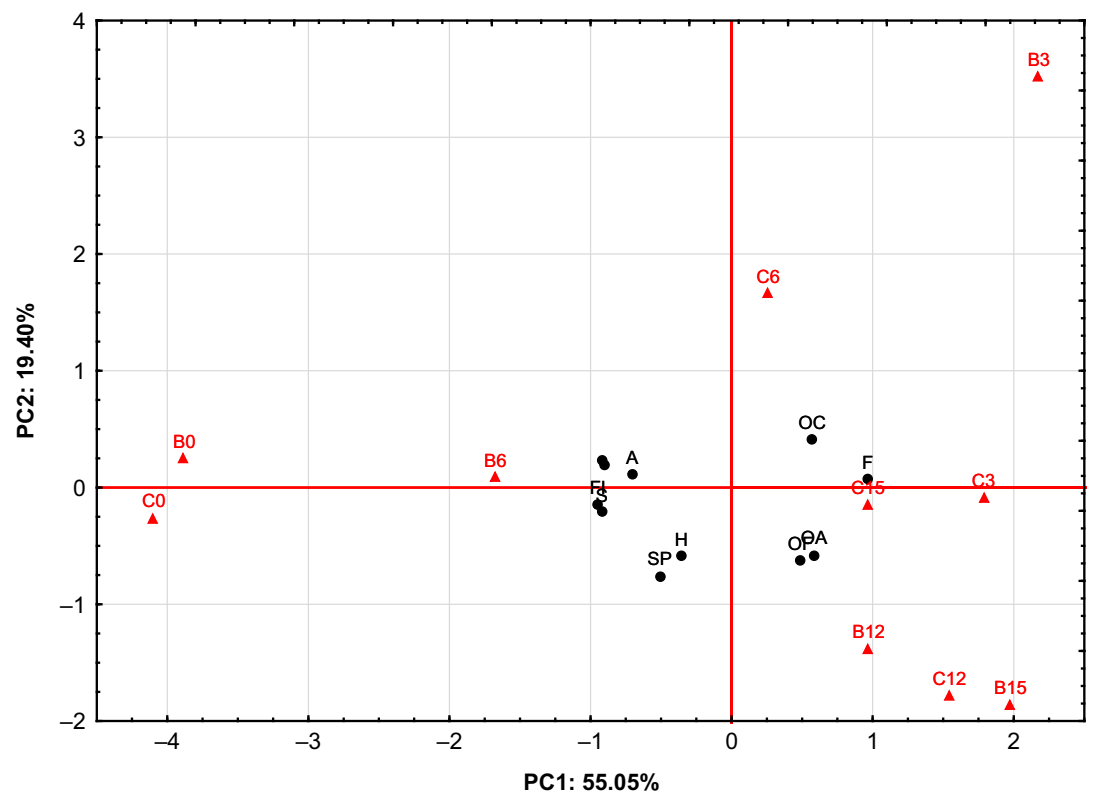

were never perceived in our samples. Although, at later storage stages, in particular at 12 and 15 months, residual off flavours have emerged, this was not the only factor contributing to lower ratings assigned to these samples, as the overall appreciation negatively correlated both with fibrousness $(r=-0.59)$ and off flavours $(r=-0.45)$. Despite no changes have been noticed in products hardness throughout storage, a significant $(P<0.05)$ correlation was found between hardness and other assessed attributes such as fibrousness $(r=0.378)$, succulence $(r=-0.366)$ and overall appreciation $(r=0.304)$.

Based on the sensory evaluation results, undesirable sensory changes resulting from oxidation processes with time, namely the development of off aromas, off flavours and off colours, were negligible (Table 5). Similar results about rancidity in cooked meat products chilled stored for 120 days have been reported by del Olmo et al. (2014). Such minor changes might indicate the antioxidant activity of some products of Maillard reactions; however, a possible masking effect from the seasoning used must also be considered.

Regarding principal component analysis, two main factors explain $74.45 \%$ of the observed variance, where $\mathrm{PC} 1$ accounts for $55.05 \%$ and $\mathrm{PC} 2$ to $19.40 \%$. The factors that significantly contribute for PC1 are aroma intensity, fibrousness, succulence, flavour intensity and overall appreciation, while PC2 includes appearance and salt perception. An important correlation is observed for aroma intensity, flavour intensity, succulence, overall appreciation (Fig. 2), which in turn correlate time zero control and BHT samples, but also with 6-month-old BHT samples (second and third quadrants) (Fig. 2). For these three sample types, ratings assigned to the overall appreciation, aroma and flavour intensity and juiciness were quite identical. Likewise, their positioning in the fourth quadrant of the principal component analysis (Fig. 2) also shows that the appearance of undesirable aromas and flavours occurred mainly in samples stored for 12 and 15 months, which have certainly contributed to lowering overall appreciation. In fact, such results are highlighted by a negative Pearson's correlation $(P<0.05)$ between TBARS results and overall appreciation $(r=-0.301)$.

\section{Conclusions}

In summary, physicochemical and microbiological results for the development of a long-life vacuumpackaged RTE meat product, carne do alguidar, evidenced that the quality of this product was maintained throughout the storage period. On the other hand, lipid oxidation results and sensory evaluation revealed the high quality and stability of this seasoned meat product over a period of up to 12 months, which can be considered an extended shelf life for this type of product. These results encourage the transfer of the carne do alguidar process technology to meat-processing factories to be manufactured at the industrial scale without the use of antioxidants. Considering that BHT was the only additive studied, and that it was concluded to be unnecessary, this traditional RTE product can be produced free of food additives. 


\section{Acknowledgments}

The authors acknowledge financial support provided by PRODER 13.021 (QREN/PRODER/Medida 4.1), Programa Operacional Regional do Alentejo (InAlentejo) ALENT-07-062-FEDER-001871 (Laboratório de Biotecnologia Aplicada e Tecnologias Agro-Ambientais) and also by FCT (Fundação para a Ciência e a Tecnologia) under the Strategic Project PEst-OE/AGR/ UI0115/2014 and co-funded by FEDER funds through the COMPETE Programme. The authors also wish to thank PALADARES ALENTEJANOS, Lda. for their collaboration and A. Oliveira and G. Pias for their technical assistance.

\section{References}

Cachaldora, A., Garcia, G., Lorenzo, J.M. \& Garcia-Fontan, M.C. (2013). Effect of modified atmosphere and vacuum packaging on some quality characteristics and the shelf-life of "morcilla", a typical cooked blood sausage. Meat Science, 93, 220-225.

EC (2005). Commission Regulation (EC) No. 2073/2005 of 15 November 2005 on microbiological criteria for foodstuffs. Official Journal of the European Union, 338, 1-26.

Fraqueza, M.J. \& Barreto, A.S. (2009). The effect on turkey meat shelf life of modified-atmosphere packaging with an argon mixture. Poultry Science, 88, 1991-1998.

ISO (1973). Meat and meat products - Determination of total fat content.

ISO (1978). Meat and meat products - Determination of nitrogen content (Reference method).

ISO (1997). Meat and meat products - Determination of moisture content (Reference method).

ISO (1998). Meat and meat products - Determination of total ash.

ISO (1999). Meat and meat products - Measurement of pH (Reference method).

ISO (2007). Animal and vegetable fats and oils - Determination of peroxide value - Iodometric (visual) endpoint determination.

ISO (2012). Sensory analysis - General guidelines for the selection, training and monitoring of selected assessors and expert sensory assessors.

ISO (2014). Microbiology of the food chain - Horizontal method for the detection and enumeration of Listeria monocytogenes and of Listeria spp. - Part 2: Enumeration method.

Jongjareonrak, A., Benjakul, S., Visessanguan, W. \& Tanaka, M. (2008). Antioxidative activity and properties of fish skin gelatin films incorporated with BHT and $\alpha$-tocopherol. Food Hydrocolloids, 22, 449-458.

Kumar, Y., Yadav, D.N., Ahmad, T. \& Narsaiah, K. (2015). Recent Trends in the Use of Natural Antioxidants for Meat and Meat Products. Comprehensive Reviews in Food Science and Food Safety, 14, 796-812.

Min, B. \& Ahn, D.U. (2015). Packaging and Storage. In: Handbook of Fermented Meat and Poultry (edited by F. Toldrá). Pp. 273-280. Oxford, UK: Wiley Blackwell.

del Olmo, A., Calzada, J. \& Nuñez, M. (2014). Effect of high-pressure-processing and modified-atmosphere-packaging on the volatile compounds and odour characteristics of sliced ready-to-eat "lacón", a cured-cooked pork meat product. Innovative Food Science \& Emerging Technologies, 26, 134-142.

Paleari, M.A., Moretti, V.M., Bersani, C., Beretta, G. \& Mentasti, T. (2004). Characterisation of a lard cured with spices and aromatic herbs. Meat Science, 67, 549-557.

Ramírez, M.R., Morcuende, D., Estévez, M. \& Cava, R. (2004). Effects of the type of frying with culinary fat and refrigerated storage on lipid oxidation and colour of fried pork loin chops. Food Chemistry, 88, 85-94.

Sacchetti, G., Di Mattia, C., Pittia, P. \& Martino, G. (2008). Application of a radical scavenging activity test to measure the total antioxidant activity of poultry meat. Meat Science, 80, 1081-1085.

Serpen, A., Gokmen, V. \& Fogliano, V. (2012). Total antioxidant capacities of raw and cooked meats. Meat Science, 90, 60-65.

Stratakos, A.C. \& Koidis, A. (2015). Suitability, efficiency and microbiological safety of novel physical technologies for the processing of ready-to-eat meals, meats and pumpable products. International Journal of Food Science \& Technology, 50, 1283-1302.

Summo, C., Caponio, F. \& Pasqualone, A. (2006). Effect of vacuum-packaging storage on the quality level of ripened sausages. Meat Science, 74, 249-254.

Timón, M.L., Broncano, J.M., Andrés, A.I. \& Petrón, M.J. (2014). Prevention of rancidity and discolouration of Iberian dry cured sausage using proteases. LWT - Food Science and Technology, 58, 293-298.

Weiss, J., Gibis, M., Schuh, V. \& Salminen, H. (2010). Advances in ingredient and processing systems for meat and meat products. Meat Science, 86, 196-213.

Wood, J.D., Richardson, R.I., Nute, G.R. et al. (2003). Effects of fatty acids on meat quality: a review. Meat Science, 66, 21-32.

Zanardi, E., Dorigoni, V., Badiani, A. \& Chizzolini, R. (2002). Lipid and colour stability of Milano-type sausages: effect of packing conditions. Meat Science, 61, 7-14.

Zanardi, E., Ghidini, S., Battaglia, A. \& Chizzolini, R. (2004). Lipolysis and lipid oxidation in fermented sausages depending on different processing conditions and different antioxidants. Meat Science, 66, 415-423. 